\title{
Influence of Magnet Material Selection on the Design of Slow-Speed Permanent Magnet Synchronous Generators for Wind Applications
}

\author{
Ants Kallaste ${ }^{1}$, Toomas Vaimann ${ }^{1,2}$, Anouar Belahcen ${ }^{1,2}$ \\ ${ }^{1}$ Department of Electrical Engineering, Tallinn University of Technology, \\ Ehitajate tee 5, 19086 Tallinn, Estonia \\ ${ }^{2}$ Department of Electrical Engineering and Automation, Aalto University, \\ PO Box 13000, 00076 Aalto, Finland \\ ants.kallaste@ttu.ee
}

\begin{abstract}
This paper analyses the influence of selected magnet materials on the design of slow-speed permanent magnet synchronous generators for use in wind applications. The design procedure, including setting of the initial design parameters of the machine, calculations of machine dimensions, magnetic flux in the air-gap, and electrical parameters as well as the selection criteria of permanent magnets for the use in the permanent magnet generator is presented. According to the calculations, a generator prototype is constructed with four different rotors, where different magnetic materials are used. The machine is tested using the different rotors and the influence of the different magnetic materials to the output characteristics of the machine is shown. The price to power analysis of the used magnetic materials is provided and conclusions for the possible machine design benefits and drawbacks are presented in the study. The investigations carried out show that $\mathrm{NdFeB}$ magnets are the preferred ones in terms of the performance and weight reduction, whereas there are considerable alternatives available, if the design and performance criteria are flexible.
\end{abstract}

Index Terms-AC machines; design methodology; generators; permanent magnets; rotors; wind energy generation.

\section{INTRODUCTION}

Wind energy is one of the most rapidly developing industries in the field of electrical engineering today [1]-[4]. This has also had major influences on the field of electrical machines, permanent magnet materials and machine design, as the everlasting search for higher energy efficiency and low cost triggered the search for alternative solutions to problem of electricity generation.

In addition to large wind farms, small-scale wind turbines (up to $100 \mathrm{~kW}$ ) that can be adapted to the electricity system of private dwellings and farms have gained a lot of popularity during the past decade [5]. The American Wind Energy Association reported 198 MW (151 300 turbines) of installed capacity of small-scale wind power in the United

Manuscript received 17 January, 2016; accepted 27 June, 2016

This work has been supported by Estonian Ministry of Education and Science base financing fund (project „Design and Optimization Methodology for Electrical Machine-Drives“").
States at the end of 2011 [5], [6]. According to the British Wind Energy Association [7], installed capacity of micro and small wind turbines in the U.K. by 2020 could be as high as 1.3 GW [8]. Based on the given reports and rules set by the European Union until the year 2020, further rise and development of small-scale wind generators is to be expected.

Permanent magnet synchronous generators are preferred in small-scale wind turbines because of their simple structure, higher efficiency and energy density, and ease of control [9]-[11]. Such generators are also preferred and most commonly used in direct-driven wind generators, in which case the slow-speed wind turbine is directly connected to the permanent magnet synchronous generator without using a gearbox [12], [13]. Omitting the gearbox is beneficial for the wind turbine system, as it increases the efficiency of the drive train and leads to minimum periodic maintenance as well as risk of failure [13]-[15].

This paper analyses the design and testing of a slow-speed directly-driven slotless permanent magnet synchronous generator. Special attention is paid to the possibility of using different permanent magnet materials within the designed machine and the influence of those chosen materials on the performances, output parameters, and cost of the generator.

The paper is organized as follows. In section II the target topological construction of the generator is explained and the mathematical model for its analysis is build. Section III explains the choice of different permanent magnet materials for the construction of the rotor of the machine. Section IV investigates the effect of different material on the output characteristics of the generator. These investigations are carried out through prototyping and testing. In section $\mathrm{V}$ the cost analysis is carried out based on the material cost and the energy efficiency of the machine.

\section{Construction And MAthematicAl Model}

To construct a suitable electrical machine, initial parameterization of the desired machine is needed after which, it will be possible to compose a mathematical model of the planned generator. These manipulations lead to the 
specification of all dimensions of the machine and analysis of the magnetic circuit of the generator. Solving of the electromagnetic calculations of the composed mathematical model, lead to the setting of generator output parameters. The construction and initial testing of the first prototype of the described machine by the authors is presented in [16].

\section{A. Initial Parameters}

Setting of the initial design parameters of the generator begins with choosing the needed power rating $P_{n}$ and rotational speed $n_{n}$ of the machine as it is required from the design of the turbine, for which the generator is meant. The input voltage level $U_{\text {in }}$ of the power electronic devices, planned to be used in hand with the turbine, sets the expected output voltage level of the machine under design. The number of phases $m$, number of pole pairs $p$, number of coils $n_{c}$, pole pitch $\tau$, dimensions of magnets such as height $h_{m}$, width $w_{m}$, and length $l_{m}$, current density $j_{t}$, and fill factor $k_{f}$ in the windings are amongst the needed parameters to be set, before any model of the machine can be composed. Additionally, the initial selection of permanent magnets should be made at this stage of the design process to determine the remanence $B_{r}$ and relative permeability $\mu_{r}$ of the magnets planned to be used in the machine. These initial parameters can be used to set the initial design of the stator coils and their dimensions. A top view of the chosen coil is presented in Fig. 1.

To carry on with the analysis of the machine, it is assumed that the length of the linear part of the coil $w_{c l}$ is equal to the magnet length, so that $w_{c l}$ becomes the same as $l_{m}$. The height of the coil $h_{c w}$, insulation thickness $h_{\text {ins }}$, circumferential separation between coils $w_{c s}$, and clearance between the stator and magnet surfaces $h_{c l}$ are the next important values of the machine design to be determined. From practice it is known, that it is usually beneficial to use parallel wires in the coil windings. The number of these parallel paths is set as $n_{p}$. These initial parameters form a base from which the machine design can lead to the composing of necessary models, however, if the output characteristics do not meet the requirements, those parameters will have to be iterated during the design process.

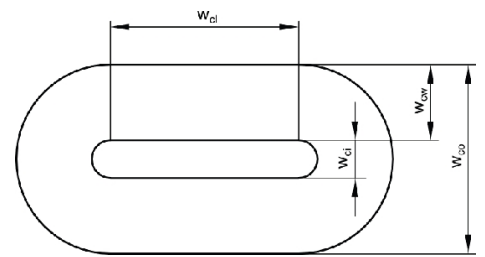

Fig. 1. Dimensions of the stator coil for the slotless generator design - top view.

\section{B. Dimensions}

In order to compose the mathematical model of the machine, the next step is to find the necessary equations and solutions for setting the needed parameterized dimensions of the generator. First, the circumferential distance between the magnets $w_{s}$ can be found as

$$
w_{s}=w_{p}-w_{m}=\frac{w_{m}}{\tau}-w_{m}=\frac{1-\tau}{\tau} w_{m},
$$

where $w_{p}$ is the width of one pole and $w_{m}$ the width of the magnet. Using the circumferential distance of the magnets, the rotor diameter $d_{r}$ can be determined as

$$
d_{r}=\frac{2 p \times w_{p}}{\pi}=\frac{2 p\left(w_{m}+w_{s}\right)}{\pi} .
$$

The air-gap for the magnetic field model $l_{g}$ is given as

$$
l_{g}=h_{c l}+h_{i n s}+h_{c w} \text {. }
$$

Next, the inner diameter of the stator $d_{s}$ can be calculated, using the rotor diameter, the height of the magnet and the length of the air-gap

$$
d_{s}=d_{r}+2\left(h_{m}+l_{g}\right)
$$

After that, dimensioning of the windings becomes possible. First, the width of the coil is found as

$$
w_{c o}=\frac{\pi d_{s}}{n_{c}}-w_{c s} .
$$

To simplify the calculations, it was found that the inner width of the coil $w_{c i}$ can be regarded as a quarter of the outer width $w_{c o}$ as this gives most suitable coil factors for the machine. Using this simplification, the cross section area of the winding $S_{c}$ can be found

$$
S_{c}=w_{c w} \times h_{c w}=\frac{w_{c o}-w_{c i}}{2} h_{c w}=\frac{3}{8} w_{c o} \times h_{c w},
$$

where $w_{c w}$ is the width of the wound part of the coil as shown on Fig. 1. To find the diameter of the winding wire $d_{t}$ to be used, another equation is constructed

$$
d_{t}=\sqrt{\frac{4}{\pi} \times \frac{P_{n}^{e}}{m \times U_{\text {in }}} \times \frac{1}{n_{p} \times j_{t}}} .
$$

Finally, the number of turns in the winding is set as

$$
n_{t}=\frac{k_{f} \times S_{c}}{n_{p} \times S_{t}}=\frac{k_{f} \times S_{c} \times 4}{n_{p} \times \pi d_{t}^{2}} .
$$

The determination of the initial parameters and dimensions of the machine yields the possibility of drawing a physical schematic of the magnets and windings as well as the stator and rotor yoke. This schematic is presented on Fig. 2 upon which the magnetic calculation is carried out.

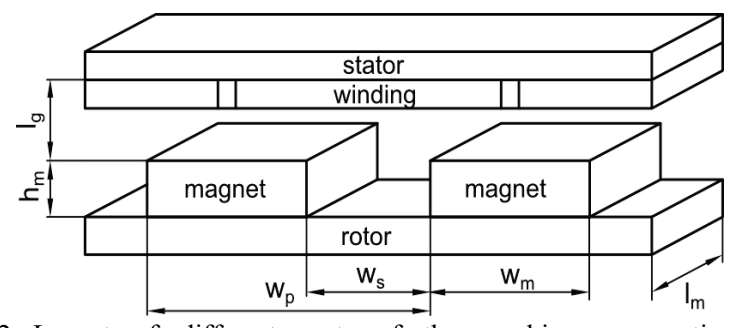

Fig. 2. Layout of different parts of the machine representing the computational model used for the solution of the magnetic field. 


\section{Magnetic Flux}

The magnetic flux in the different parts of the machine can be divided into four groups that are shown in Fig. 3. Those four parts are the magnetic flux that crosses the airgap $\Phi_{g}$, the leakage flux on both sides of the magnet $\Phi_{l}$, the leakage flux to the consecutive pole $\Phi_{s}$, and remanence flux $\Phi_{r}$, produced by the permanent magnet and that can be described as the sum of the previously defined three magnetic fluxes.

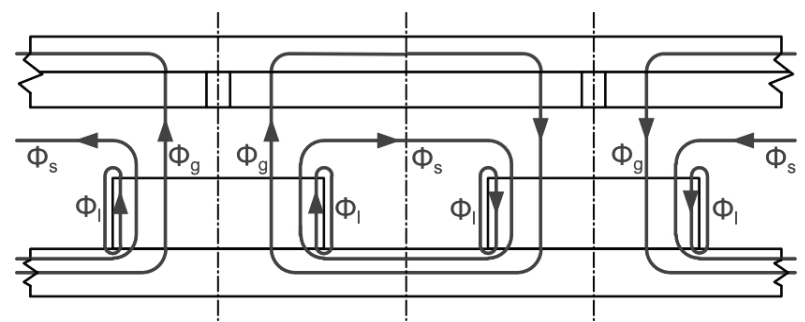

Fig. 3. Magnetic fluxes and their paths.

To compose and solve the magnetic circuit of the machine, first, construction of an equivalent magnetic circuit is needed. This comes with additional simplifications in some parameters. The non-linear permeances of steel laminations are larger than the other permeances by several orders of magnitude and thus will be disregarded in a first approach. As the circuit is symmetrical the magnetic circuit model can be further simplified by splitting the circuit along the symmetry axis. The equivalent magnetic circuit composed for the generator is presented in Fig. 4.

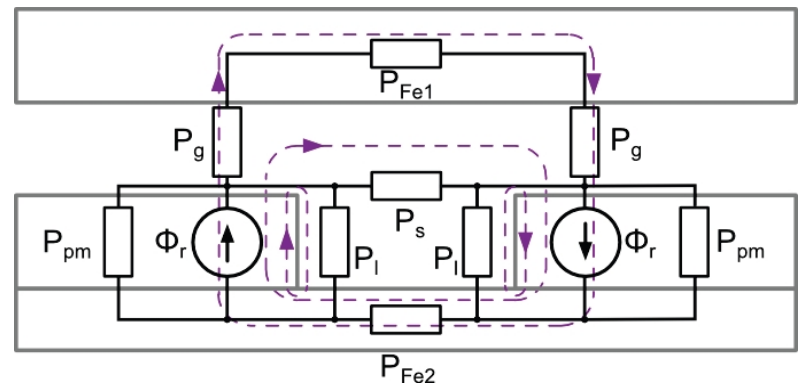

Fig. 4. Equivalent circuit to calculate the magnetic flux in the air-gap.

The determination of the magnetic circuit parameters for the considered machine begins with defining the permeance of the magnet $P_{p m}$

$$
P_{p m}=\mu_{0} \mu_{r} \times \frac{A_{p m}}{h_{m}}=\mu_{0} \mu_{r} \times \frac{l_{m} \times w_{m}}{h_{m}},
$$

where $A_{p m}$ describes the surface area of the magnet. The leakage flux on magnet sides corresponds to the permeance $P_{l}$

$$
P_{l}=\frac{\mu_{0} l_{m}}{\pi} \int_{0}^{\frac{w_{m}}{2}} \frac{d x}{x+\frac{h_{m}}{\pi}}=\frac{\mu_{0} l_{m}}{\pi} \times \ln \left(1+\frac{\pi w_{m}}{2 h_{m}}\right)
$$

In a similar way the permeance for the air-gap leakage $P_{s}$ is calculated as

$$
P_{S}=\frac{\mu_{0} l_{m}}{\pi} \int_{0}^{l_{g}} \frac{d x}{x+\frac{w_{s}}{\pi}}=\frac{\mu_{0} l_{m}}{\pi} \times \ln \left(1+\frac{\pi l_{g}}{w_{s}}\right) .
$$

The permeance for the air-gap flux $P_{g}$ is given as

$$
P_{g}=\mu_{0} \times \frac{A_{p m}}{l_{g}}=\mu_{0} \times \frac{l_{m} \times w_{m}}{l_{g}} .
$$

Finally, the magnetic flux in the air-gap $\Phi_{g}$ can be calculated as

$$
\Phi_{g}=\Phi_{r} \times \frac{P_{g}}{P_{\Sigma}}=\frac{B_{r} \times l_{m} \times w_{m} \times P_{g}}{P_{p m}+P_{l}+\frac{P_{s}}{2}+P_{g}},
$$

where $P_{\Sigma}$ is the resulting permeance of the split circuit.

\section{Electrical Parameters}

Taken into account the calculated value of the magnetic flux in the air-gap of the machine, setting of the electrical parameters can be carried out as follows. First, the EMF value of a single phase $E$ at a certain frequency $f$ can be defined

$$
E(f)=\frac{\sqrt{2} \pi n_{c} n_{t} k_{w} \Phi_{g}}{m} f,
$$

where $k_{w}$ is the winding factor. To simplify the calculation of the output voltages and load currents of the generator, as well as analysing the operation of the machine, an equivalent circuit is used. This circuit is presented in Fig. 5 [17].

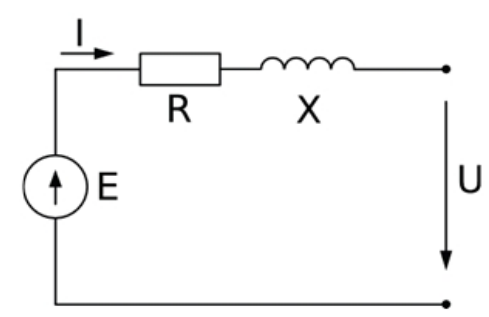

Fig. 5. Equivalent circuit for one phase of the generator.

The phase resistance $R$ is calculated as

$$
R=\rho \times \frac{n_{t}\left(2 w_{c l}+\pi \frac{5}{8} w_{c o}\right)}{S_{t} \times n_{p}} \times \frac{n_{c}}{m},
$$

where $\rho$ denotes the resistivity of the winding material.

The reactance per phase $X$ at a certain frequency $f$ is calculated as

$$
X(f)=\frac{2 \pi L_{c} n_{c}}{m n_{p}} f
$$

where $L_{c}$ is the inductance of a single coil. The inductance is calculated using an empirical formula for a multilayer air- 
core coil [16] as

$$
L_{c}=\frac{40 r_{e q}^{2} \times n_{t}^{2}}{6 r_{e q}+9 l_{c}+10 w_{c w}}[\mathrm{mH}] .
$$

where $r_{e q}$ is the equivalent radius of the coil and $l_{c}$ denotes the total length of the wire in the winding. Those parameters are obtained using the dimensions of the coil, found in the above calculations. To find the voltage in the equivalent circuit, the following equation based on the equivalent circuit of Fig. 5 is used where output voltage depends on the generator power level and frequency

$$
U(P, f)=E(f)-j X(f) I(P)-R I(P) .
$$

Voltage and current calculation of the circuit must be carried out using iterations, hence phase current $I$ at a certain power level for iteration $i$ is

$$
I_{i}(P)=\frac{P_{i}}{m \times U_{i-1}} .
$$

For evaluation the output parameters of the designed generator at different power levels and frequencies (18) is transformed and written as follows

$$
U_{i-1}=E_{i}-j X_{i} I_{i}-R I_{i}
$$

Solving (20) for different power levels will result in obtaining the output characteristics of the designed machine.

Finally, the rated frequency of the generator $f$ can be calculated

$$
f_{i}=\frac{n_{i-1} \times p}{60}
$$

Iteration is carried out for the generator from no load up to maximum power level (19) and from standstill up to maximum rotational speed (21).

\section{E. Construction of the Machine}

Taken into account the described calculations to determine the initial parameters of the design, a machine was constructed. The designed machine is a radial flux permanent magnet generator. The main characterizing feature of such machine design is a relatively small axial length and large diameter of the generator. The construction schematic of the machine is presented in Fig. 6 and the main parameters are given in Table I.

TABLE I. MAIN DATA OF THE DESIGNED MACHINE.

\begin{tabular}{|c|c|c|}
\hline Parameter & Symbol & Value \\
\hline Rated power & $P_{n}$ & $5 \mathrm{~kW}$ \\
\hline Rated speed & $n_{n}$ & $230 \mathrm{rpm}$ \\
\hline Rated voltage & $U_{n}$ & $240 \mathrm{~V}_{\mathrm{ac}}$ \\
\hline Rated current & $I_{n}$ & $12.1 \mathrm{~A}_{\mathrm{ac}}$ \\
\hline Number of stator coils & $Q_{s}$ & 24 \\
\hline Number of rotor poles & $2 p$ & 40 \\
\hline Generator diameter & $d_{g}$ & $690 \mathrm{~mm}$ \\
\hline Width of the air-gap & $d_{a g}$ & $2.5 \mathrm{~mm}$ \\
\hline
\end{tabular}

To avoid the undesired cogging torque phenomenon, a slotless design was implemented. This means that the windings of the machine stator are concentrated and housed in the resin. Figure 7 illustrates the slotless design concept.

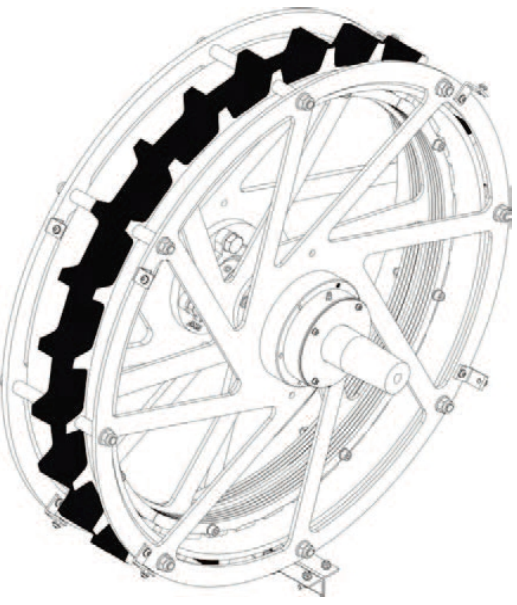

Fig. 6. Constructional schematic of the designed generator.

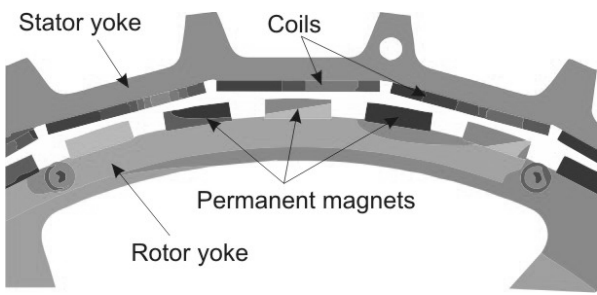

Fig. 7. Principle of the slotless design concept.

\section{F. Validation of the Model}

The analytical model presented in the paper was verified by comparing the calculated air-gap flux to the value obtained from FEM analysis. The resulting error of this comparison was less than $5 \%$.

To validate the model of the designed machine, tests were performed using the constructed prototype machine. The results of the tests are presented on Fig. 8 and Fig. 9.

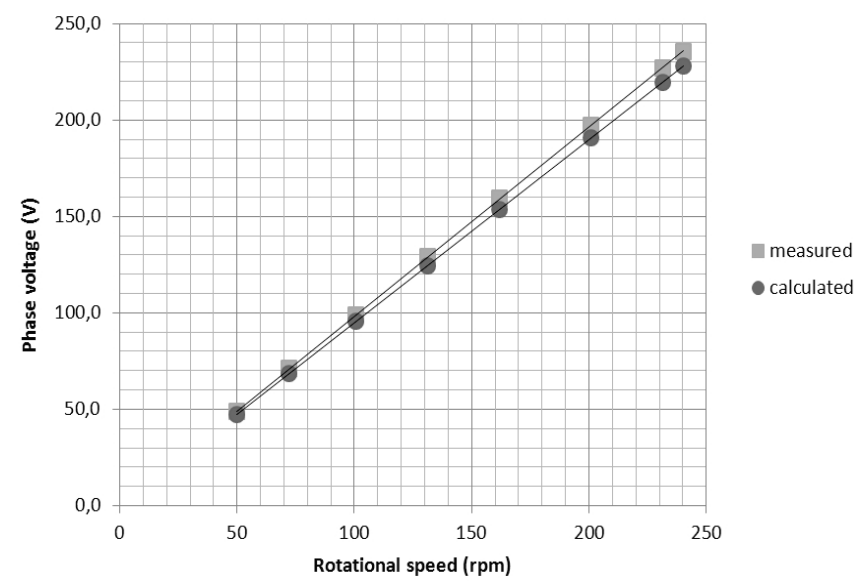

Fig. 8. No load test - measured results versus calculated values.

As presented on the results of the no load test, Fig. 8, calculated and measured values vary in a very little scale. The obtained characteristic is relatively linear, as was also expected. In the case of load tests, Fig. 9, the difference between calculated and measured values is bigger. The deviation increased with the increase of the load and it can be noted, that measured values in this case are lower than the calculated ones. 


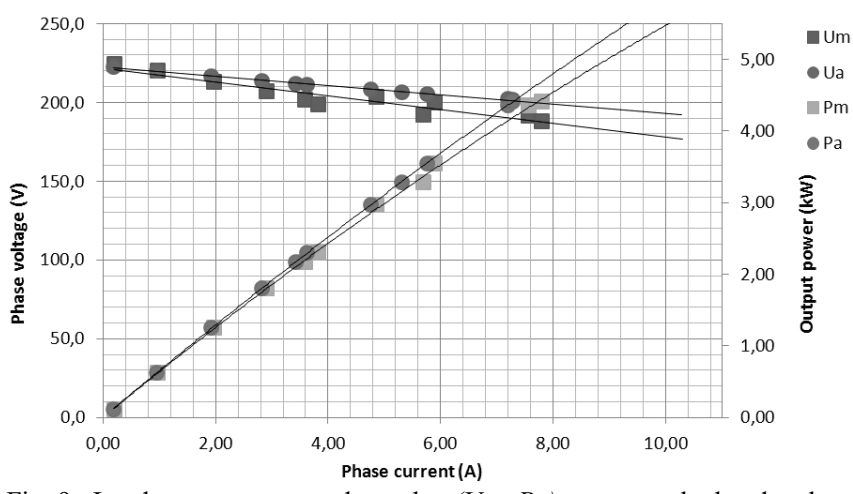

Fig. 9. Load test - measured results $\left(U_{m}, P_{m}\right)$ versus calculated values $\left(U_{a}, P_{a}\right)$.

\section{Selection of Permanent Magnets}

To choose an appropriate permanent magnet material to design an electric machine might not always be an easy task. Mainly there are three properties that have to be taken into account in the technical perspective of the design. These are energy density, coercivity and remanence of permanent magnet materials. Practical aspects add another variable to the line, namely the price of the magnet.

There are three main permanent magnet materials available that can be chosen as the sufficient magnet for the use in electrical machines. The main properties of those materials are presented in Table II. From these four, ferrite and AlNiCo magnets are the weakest in all the mentioned criteria, except the price, which is remarkably lower than in case of $\mathrm{NdFeB}$ or $\mathrm{SmCo}$ alloys. $\mathrm{NdFeB}$ magnets have traditionally the best properties amongst the four listed materials. SmCo magnets on the other hand have better temperature range, and thus can be used in special applications, where $\mathrm{NdFeB}$ permanent magnets cannot be applicable. The high price of SmCo materials is usually the aspect that hinders the wider and more common use of the material.

TABLE II. PROPERTIES OF THE MAIN PERMANENT MAGNET

\begin{tabular}{|c|c|c|c|}
\multicolumn{4}{|c|}{ MATERIALS [18]. } \\
\hline Material & $\boldsymbol{B H}_{\boldsymbol{m a x}}\left(\mathbf{k J} / \mathbf{m}^{\mathbf{3}}\right)$ & $\boldsymbol{B}_{\boldsymbol{r}}(\mathbf{T})$ & $\boldsymbol{H}_{\boldsymbol{c}}(\mathbf{k A} \mathbf{m} \mathbf{m})$ \\
\hline NdFeB & $220-500$ & $0.97-1.45$ & $740-1000$ \\
\hline SmCo & $120-240$ & $0.85-1.1$ & $620-840$ \\
\hline Ferrite & $7-42$ & $0.2-0.48$ & $120-360$ \\
\hline AlNiCo & $10-35$ & $0.6-1.16$ & $40-120$ \\
\hline
\end{tabular}

In case of using the lower energy density magnets, like ferrite or AlNiCo, there are still various possibilities to improve the magnetic flux density in the air-gap. Some of the possibilities include $\mathrm{V}$-shape magnet configuration or mounting the magnets in Halbach array, to concentrate the magnetic flux density [19], [20]. However, the implementation of such methods also means that larger quantities of the magnetic materials must be used and thus results in rising of the weight of the machine and its cost [21].

Since the start of their usage, $\mathrm{NdFeB}$ permanent magnet materials have had by far the highest energy density. Due to this fact, $\mathrm{NdFeB}$ has become the most preferred and desired permanent magnet material in the electrical machine industry. The main drawbacks of this material come from the relatively closed production market of the alloy, which can lead to unexpected price deviations. This phenomenon is the key issue, why the use of other permanent magnet materials must also be considered in the design of electrical machines. Fig. 10 illustrates the maximum energy product of magnets throughout the years when development of permanent magnet materials has been going on.

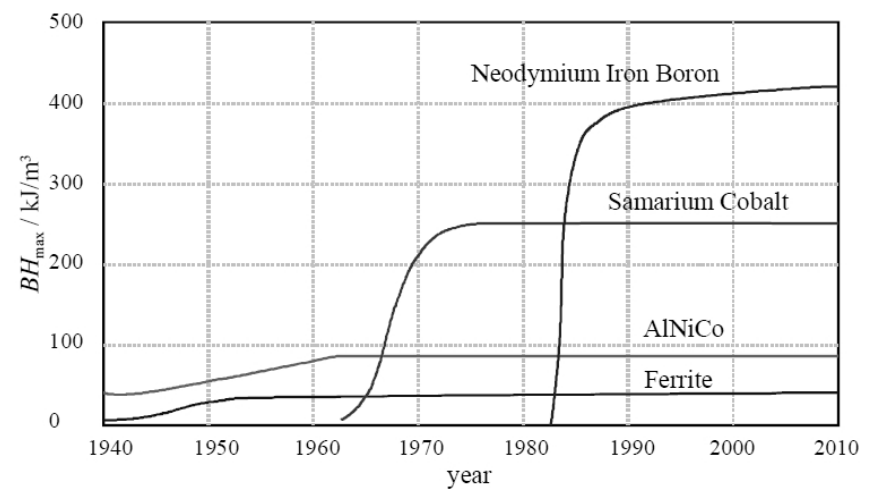

Fig. 10. Maximum energy product $B H_{\max }$ development of permanent magnet materials throughout the years [22].

Based on the information of the magnetic material selection and initial parameters calculation, magnetic materials to construct the machine, as well as the sizes and amount of corresponding magnets were chosen. The dimensions and quantity needed to construct the designed rotors for the generator are presented in Table III.

TABLE III. DIMENSIONS AND QUANTITY OF THE CHOSEN MAGNETS

\begin{tabular}{|c|c|c|c|}
\hline \multicolumn{2}{|c|}{ Magnet } & Dimensions (mm) & Quantity \\
\hline \multicolumn{2}{|c|}{$\mathrm{NdFeB}$} & $35 \times 55 \times 10$ & 40 \\
\hline \multicolumn{2}{|c|}{ SmCo } & $40 \times 55 \times 15$ & 40 \\
\hline \multicolumn{2}{|c|}{ Ferrite } & $100 \times 40 \times 40$ & 32 \\
\hline \multirow{2}{*}{$\begin{array}{c}\text { Ferrite } \\
\text { (Halbach) }\end{array}$} & Main magnet & $100 \times 40 \times 40$ & 32 \\
\hline & Side magnet & $100 \times 39 \times 23$ & 32 \\
\hline
\end{tabular}

\section{INFLUENCE OF PERMANENT MAGNETS ON THE OUTPUT CHARACTERISTICS OF THE MACHINE}

To test the influence of magnetic material selection on the output parameters and characteristics of the designed machine, four different rotors were constructed to be used with the same stator. The magnetic materials used in those rotors were $\mathrm{NdFeB}, \mathrm{SmCo}$ and ferrite. There were two different rotors equipped with ferrite magnets. One of them was built using a traditional layout of magnets, and the other one using the Halbach array.

Halbach array is a special layout of magnets, in order to achieve high efficiency and high power density of the machine, especially when using lower energy density magnets [20], [23], [24]. The mean for that is the raising of the magnetic flux density in the air-gap of the machine. Although having many advantages, using Halbach array also poses a demagnetizing risk of the used magnets already in the construction process of the machine, because the interaction between the different magnets adds to the stress on the magnets [20], [21]. However, in case of the designed machine, the possible gain of using Halbach array instead of the traditional layout of the low grade magnets, is higher than the probability of the undesired demagnetization of the magnets. The principle of Halbach array is presented in 
Fig. 11.

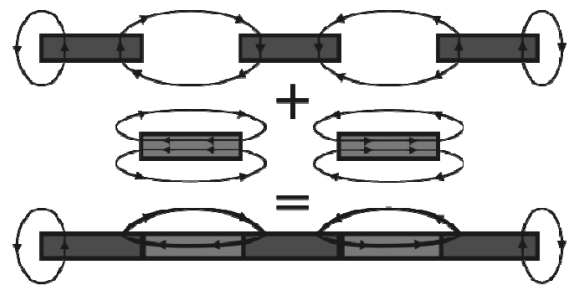

Fig. 11. Working principle of Halbach array. The insertion of magnets with different magnetization directions produces a field concentration that increases the air-gap flux density [19].

Using all four of the designed and constructed rotors, no load tests of the generator were performed. As can it can be found on Fig. 12, the phase voltages correlate to the energy density of the materials as it is presented in Fig. 10. Additionally, it can be observed that raising the magnetic flux in the air-gap using Halbach array also raises the gained phase voltage of the corresponding machine. Further, the difference between phase voltages in case of different magnetic materials is rising, as the rotational speed of the machine increases.

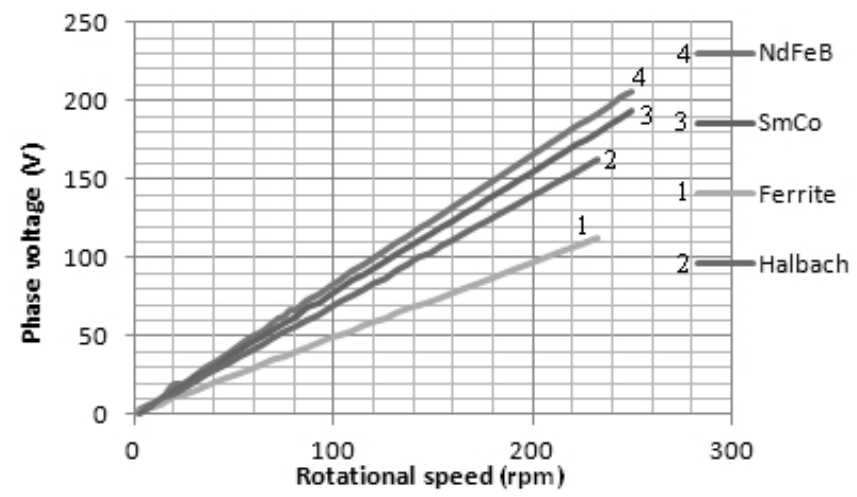

Fig. 12. Measured no load phase voltages of the designed generator in case of different magnetic materials.

Load tests at the rated speed of the designed generator were carried out too. Figure 13 shows that a dropping of the phase voltage can be distinguished during the increase of the current. The trends of these voltage drops are relatively similar but the main difference can be observed in the value of the phase voltage itself. Usage of lower grade magnets in the machine tends to result in a lower phase voltage at the same given current as when high energy density magnets are used.



Fig. 13. Measured phase voltage versus phase current characteristics of the designed generator in case of different magnetic materials.

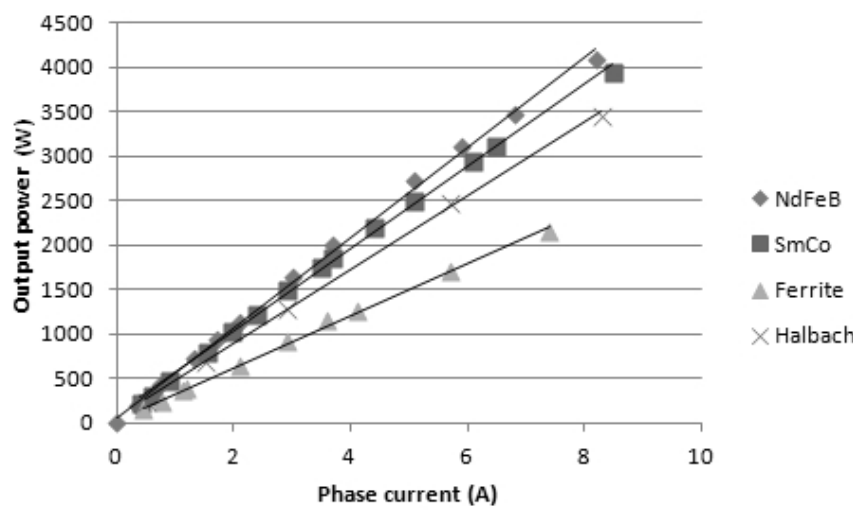

Fig. 14. Measured output power versus phase current characteristics of the designed generator in case of different magnetic materials.

Figure 14 shows the output power and phase current dependency from the used magnetic material. From these tests the main conclusion would be that it is generally problematic to achieve the rated power using very low grade magnets, even if the dimension of the magnets is set by calculations. Machine using lower grade magnets has always lower output power at the same phase current as the ones with higher energy density magnets or lower grade magnets mounted in the machine using special layout concepts.

\section{Cost-EFFICIENCY AnALYSis of the Machine IN CASE OF DiFFERENT MAGNETIC MATERIALS}

Ferrite magnets, although considerably weaker and lower grade than rare earth magnetic materials, continue to dominate the global sales on the material weight basis and it represents around $80 \%$ of the permanent magnets sold around the world [25]. On the other hand, with the development of information technologies and electrical engineering sector, there is a high and growing demand of high energy density magnets that have considerably smaller mass and dimensions. The main trigger for such a need is the fast spread of green technologies and the global orientation towards energy efficiency. Due to this, the NdFeB magnets represent over half of all magnet sales on monetary basis.

Recent years have been very unstable in the rare earth magnetic material market. Although researches show that the supply of neodymium (Nd) would last at least for 1000 years, when compared to present consumption [26], the instability of the market is not very likely to change too much, due to the lack of suitable mining sites. As mainly the mining sites of $\mathrm{Nd}$ and many other rare earth materials are situated in China, the development of its national economy and growing demand of the rare earth material supplies will decrease the export amounts of the materials and influence the prices.

These phenomena led to a very rapid price growth of $\mathrm{Nd}$ materials in 2011. The graph of the price level of $\mathrm{Nd}$ is presented in Fig. 15. However, the global demand for $\mathrm{Nd}$ magnets continues to increase worldwide, which might very easily lead to a new rise in the price for Nd. Such uncertainties of the market have initiated the growth in research of alternative magnetic materials.

According to the market standings in May 2014, when these calculations were performed, the cost of $\mathrm{NdFeB}$ magnets used in the designed machine was approximately 
1768 USD. The price of SmCo magnets for the same generator was 1927 USD. Historically, and in the normal market situations, SmCo has always been more expensive than $\mathrm{NdFeB}$, as it is also in the given example, where $\mathrm{SmCo}$ magnets cost approximately $10 \%$ more than $\mathrm{NdFeB}$ magnets. It usually becomes price and performance competitive in the temperature range between $150{ }^{\circ} \mathrm{C}$ and $180^{\circ} \mathrm{C}$, where the use of $\mathrm{NdFeB}$ becomes problematic due to the risk of demagnetization. However, during the rapid rise of the $\mathrm{Nd}$ price in 2011, SmCo became cheaper than $\mathrm{NdFeB}$, which made it a more affordable magnet to use. Similar phenomena may occur in the future, resulting in large scale price fluctuations in the rare earth material market.

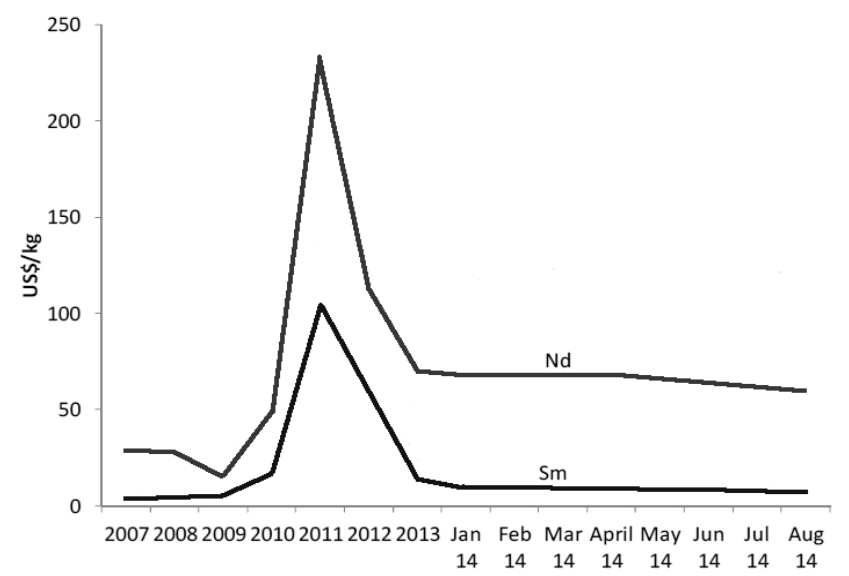

Fig. 15. Price of Nd and Sm metal [27].

The cost of magnetic material using ferrite magnets in traditional radial layout is 1063 USD, but the mass of used magnetic material in order to achieve better performance of the machine is rising quickly. Hence, it can be said that ferrite becomes competitive only when special layouts are used and the size and weight of the product is not strictly limited [28].

TABLE IV. PRICES OF THE MAGNETS USED IN THE DESIGNED MACHINE.

\begin{tabular}{|c|c|}
\hline Magnet material & Price (USD) \\
\hline $\mathrm{NdFeB}$ & 1768 \\
\hline SmCo & 1927 \\
\hline Ferrite & 1063 \\
\hline Ferrite (Halbach) & 1663 \\
\hline
\end{tabular}

The price of side magnets is an additional 600 USD and the value of magnetic material using Halbach array sums up to 1663 USD. It is considerably lower than in case of SmCo magnets and slightly less than the price of $\mathrm{NdFeB}$ magnets. When the additional size, weight and complexity of building is taken into account, the cost of the generator using ferrite magnets might outpace the cost of generators using SmCo or $\mathrm{NdFeB}$ magnets, due to the additional mass added to the whole setup by the lower grade magnets. To have a better visual overview of the prices, the cost of different magnetic materials in the designed machine is also presented in Table IV.

It should be noted however, that in this analysis only the price of magnetic material is compared to each other. No additional costs due to the changing weight and construction of the wind turbine, where such machines could be implemented, have been taken into account.

\section{CONCLUSIONS}

The calculated electrical parameters of the machine were evaluated by testing the designed and constructed generator. The difference between the calculated and measured phase voltages was very small. The largest difference between the calculated and measured values could be seen at higher loads during the load tests of the machine. With rising of the load, the difference between calculated and measured value was also increasing. This was most probably caused by the inaccuracies of the inductance calculations.

In general, the presented method for setting initial design parameters, calculating dimensions of the machine, magnetic flux in the air-gap and electrical parameters of the generator can be considered usable as the first approximation that should always be done in the first phase of machine design. It can also be used as a simplified model to evaluate similar multi-pole slotless permanent magnet generators, regardless of their exact design and used magnetic materials.

When the evaluation of the performance of the designed machine is made, it can be seen that the best output characteristic results are reached using $\mathrm{NdFeB}$ magnets. These high energy density magnets are providing the best results regarding the electrical parameters and taken into account the market situation at the time of cost-efficiency calculations, $\mathrm{NdFeB}$ magnets also had the best price to power ratio.

However, NdFeB magnets have some considerable alternatives that can be used in a synchronous generator. Power characteristics and the construction price of similar generator using SmCo magnets are not very far apart from the NdFeB magnet machine. The substitution of $\mathrm{NdFeB}$ magnets can also prove beneficial taking into account the unstable prices of the rare earth magnets, which would make alternative materials more reasonable to use.

Ferrite can compete with high density magnetic materials only when special layout, like Halbach array, is used to raise the magnetic flux density in the air-gap of the machine. As the magnetic material mass in case of ferrite magnets is considerably higher, also the weight of the machine, and from this, the whole construction of the wind turbine rises significantly. Hence, ferrite magnets can only be competitive when the size and weight of the final product is not strictly limited, even when special layouts of the magnets are implemented.

\section{ACKNOWLEDGMENT}

Authors would like to thank my!Wind Llc. for their help and support in the building of the prototype generator.

\section{REFERENCES}

[1] S. Xu, A. Q. Huang, W. Fei, R. Burgos, "Wind energy system with integrated functions of active power transfer, reactive power compensation, and voltage conversion", IEEE Trans. Industrial Electronics, vol. 60, no. 10, pp. 4512-4524, 2013. [Online] Available: https://doi.org/10.1109/TIE.2012.2216245

[2] M. Liserre, R. Cardenas, M. Molinas, J. Rodriguez, "Overview of multi-MW wind turbines and wind parks", IEEE Trans. Industrial Electronics, vol. 58, no. 4, pp. 1081-1095, 2011. [Online]. Available: 
https://doi.org/10.1109/TIE.2010.2103910

[3] L. Barote, C. Marinescu, M. N. Cirstea, "Control structure for singlephase stand-alone wind-based energy sources", IEEE Trans. Industrial Electronics, vol. 60, no. 2, pp. 764-772, 2013. [Online]. Available: https://doi.org/10.1109/TIE.2012.2206346

[4] J. Chen, J. Chen, C. Gong, "On optimizing the aerodynamic load acting on the turbine shaft of PMSG-based direct-drive wind energy conversion system," IEEE Trans. Industrial Electronics, vol. 61 no. 8, pp. 4022-4031, 2014. [Online]. Available: https://doi.org/ 10.1109/TIE.2013.2284148

[5] R. Cisneros, F. Mancilla-David, R. Ortega, "Passivity-based control of a grid-connected small-scale windmill with limited control authority", IEEE Journal of Emerging and Selected Topics in Power Electronics, vol. 1, no. 4, pp. 247-259, 2013. [Online]. Available: https://doi.org/10.1109/JESTPE.2013.2285376

[6] American Wind Energy Association (AWEA). 2011 U.S. Small Wind Turbine Market Report, Washington, DC, USA.

[7] BWEA, Small Wind Systems, U.K. Market Report, U.K., 2010.

[8] J. L. Acosta, K. Combe, S. Z. Djokic, I. Hernando-Gil, "Performance assessment of micro and small-scale wind turbines in urban areas", IEEE Systems Journal, vol. 6, no. 1, pp. 152-163, 2012. [Online] Available: https://doi.org/10.1109/JSYST.2011.2163025

[9] M. Chinchilla, S. Arnaltes, J. C. Burgos, "Control of permanentmagnet generators applied to variable-speed wind-energy systems connected to the grid", IEEE Trans. Energy Conversion, vol. 21 , no. 1, pp. $130-135,2006$. [Online]. Available: https://doi.org/ 10.1109/TEC.2005.853735

[10] Y. Xibo, W. Fei, D. Boroyevich, L. Yongdong, R. Burgos, "DC-link voltage control of a full power converter for wind generator operating in weak-grid systems", IEEE Trans. Power Electronics, vol. 24 no. 8, pp. 2178-2192, 2009. [Online]. Available: https://doi.org/ 10.1109/TPEL.2009.2022082

[11] Z. Dalala, Z. Zahid, J. Lai, "New overall control strategy for smallscale WECS in MPPT and stall regions with mode transfer control", IEEE Trans. Energy Conversion, vol. 28, no. 4, pp. 1082-1092, 2013. [Online]. Available: https://doi.org/10.1109/TEC.2013. 2287212

[12] H. Li, Z. Chen, "Overview of different wind generator systems and their comparisons", IET Renewable Power Generation, vol. 2, no. 2 , pp. 123-138, 2008. [Online]. Available: https://doi.org/10.1049/ietrpg:20070044

[13] J. Sopanen, V. Ruuskanen, J. Nerg, J. Pyrhonen, "Dynamic torque analysis of a wind turbine drive train including a direct-driven permanent-magnet generator", IEEE Trans. Industrial Electronics, vol. 58, no. 9, pp. 3859-3867, 2011. [Online]. Available: https://doi.org/10.1109/TIE.2010.2087301

[14] H. Polinder, F. F. A. van der Pijl, G.-J. de Vilder, P. J. Tavner, "Comparison of direct-drive and geared generator concepts for wind turbines", IEEE Trans. Energy Conversion, vol. 21, no. 3, pp. 725733, 2006. [Online]. Available: https://doi.org/10.1109/TEC. 2006.875476
[15] M. Molinas, J. A. Suul, T. Undeland, "Extending the life of gear box in wind generators by smoothing transient torque with STATCOM", IEEE Trans. Industrial Electronics, vol. 57, no. 2, pp. 476-484, 2010. [Online]. Available: https://doi.org/10.1109/TIE.2009.2035464

[16] K. Tuttelberg, A. Kallaste, T. Vaimann, "Analysis of a slow-speed slotless permanent magnet synchronous generator", in Proc. of 4th Int. Youth Conf. Energy, 2013, pp. 1-5. [Online]. Available: https://doi.org/10.1109/iyce.2013.6604187

[17] V. Ostovic, Computer-aided Analysis of Electric Machines: A Mathematica approach. Hemel Hempstead: Prentice Hall International Ltd, 1994, p. 191.

[18] P. Sekerak, V. Hrabovcova, M. Onufer, L. Kalames, P. Rafajdus, "Synchronous motors with different PM materials", in Proc. of 9th Int. Conf. ELEKTRO, 2012, vol. 3, pp. 241-246. [Online]. Available: https://doi.org/10.1109/elektro.2012.6225646

[19] A. Kallaste, A. Kilk, A. Belahcen, T. Vaimann, K. Janson, "Demagnetization in permanent magnet slotless generator using Halbach array", 13th Int. Scientific Conf. Electrical Power Engineering, 2012, pp. 1053-1057.

[20] A. Kallaste, A. Belahcen, T. Vaimann, "Dynamic modeling of the demagnetization in Halbach array permanent magnet machine", 19th Int. Conf. the Computation of Electromagnetic Fields, 2013, pp. 1-2.

[21] T. Vaimann, A. Kallaste, A. Belahcen, A. Kilk, "Magnetic properties of reduced Dy $\mathrm{NdFeB}$ permanent magnets and their usage in electrical machines", in Conf. AFRICON, 2013, pp. 1124-1128. [Online]. Available: https://doi.org/10.1109/afrcon.2013.6757787

[22] Material of Magnet Technology Center at Prizztech Ltd.

[23] J. D. McFarland, T. M. Jahns, "Investigation of the rotor demagnetization characteristics of interior PM synchronous machines during fault condition", Energy Conversion Congress and Exposition (ECCE), 2012, pp. 4021-4028.

[24] K. C. Kim, K. Kim, H. J. Kim, J. Lee, "Demagnetization analysis of permanent magnets according to rotor types of interior permanent magnet synchronous motor", IEEE Trans. Magnetics, vol. 45 , no. 6 , pp. 2799-2802, 2009. [Online]. Available: https://doi.org/10.1109/ TMAG.2009.2018661

[25] The Powder Metallurgy Industry in the UK - the next ten years. The Institute of Materials, 2000, p. 60.

[26] J. Pyrhonen, J. Nerg, P. Kurronen, J. Puranen, M. Haavisto, "Permanent magnet technology in wind power generators", in Proc. of 19th Int. Conf. Electrical Machines, 2010, pp. 1-6. [Online]. Available: https://doi.org/10.1109/icelmach.2010.5608312

[27] N. Haque, A. Hughes, S. Lim, C. Vernon, "Rare earth elements: overview of mining, mineralogy, uses, sustainability and environmental impact", Resources, vol. 4, no. 3, pp. 614-635, 2014. [Online]. Available: https://doi.org/10.3390/resources3040614

[28] S. Laurit, A. Kallaste, T. Vaimann, A. Belahcen, "Cost efficiency analysis of slow-speed slotless permanent magnet synchronous generator using different magnetic materials", in Proc. of 9th Electric Power Quality and Supply Reliability Conf., 2014, pp. 221-224. [Online]. Available: https://doi.org/10.1109/pq.2014.6866814 